This item was submitted to Loughborough's Research Repository by the author.

Items in Figshare are protected by copyright, with all rights reserved, unless otherwise indicated.

\title{
Textile-to-rigid microstrip transition using permanent magnets
}

\section{PLEASE CITE THE PUBLISHED VERSION}

http://dx.doi.org/10.1049/el.2014.4361

\section{PUBLISHER}

(c) Institution of Engineering and Technology (IET)

\section{VERSION}

AM (Accepted Manuscript)

\section{PUBLISHER STATEMENT}

This work is made available according to the conditions of the Creative Commons Attribution-NonCommercialNoDerivatives 4.0 International (CC BY-NC-ND 4.0) licence. Full details of this licence are available at: https://creativecommons.org/licenses/by-nc-nd/4.0/

\section{LICENCE}

CC BY-NC-ND 4.0

\section{REPOSITORY RECORD}

de Sousa Fonseca, Duarte M., R.D. Seager, and James A. Flint. 2019. "Textile-to-rigid Microstrip Transition Using Permanent Magnets". figshare. https://hdl.handle.net/2134/17828. 


\section{Textile-to-Rigid Microstrip Transition Using Permanent Magnets}

Fonseca, Duarte S., Seager, Robert D. and Flint, James A.

This paper describes a novel transition between a rigid-substrate and a flexible substrate microstrip for use in wearable devices. The contact force between the conductors of the two microstrips is supplied by a pair of rectangular magnets. A simulation and measurement study carried on a test jig comprising of a back-to-back pair of such transitions demonstrating an insertion loss of better than $0.5 \mathrm{~dB} /$ transition can be achieved in the range $0-3 \mathrm{GHz}$.

Introduction: With the ubiquity of the wearable electronics in the last few years, there has been increased research in the area of textile antennas [1] and transmission lines [2]. These have been successfully created using different types of materials and construction methods. However, microwave circuits are still largely rigid substrate based and thus there remains a need to achieve a low-loss and reliable connection between textile and conventional microstrip or other transmission lines. There are several works which address this problem e.g. $[3,4]$ however there is considerable scope to improve the connector performance and mechanical properties of such interconnects. The present paper presents a novel method of mechanically retaining the connection - i.e. permanent magnets - which has the benefit of not requiring any external force to be placed on the connection during attachment. This has clear advantages when considering the relatively fragile nature of microwave transmission lines implemented on a fabric substrate.

The use of magnets is presented with measurements taken for frequencies between $200 \mathrm{MHz}$ and $3 \mathrm{GHz}$. The test jig shown in Figure 1 consists of a microstrip etched on a $1.54 \mathrm{~mm}$ thick FR4 with a square area of $16 \times 25 \mathrm{~mm}$ cut from the central area of the FR4 board (Figure 2) to accommodate the textile microstrip that will bridge the gap. The textile microstrip consists of 4 layers of Denim dielectric. On the top layer a microstrip line has been embroidered using Liberator ${ }^{\mathrm{TM}}$ created by Syscom Advanced Materials [5]. On the bottom layer Shieldex ${ }^{\circledR}$ Nora Dell [6] was stitched to the denim to act as a ground plane. The textile microstrip line is $5 \mathrm{~mm}$ wide and the etched microstrip is $3 \mathrm{~mm}$ wide with a step transition between the two. The Denim substrate height is approximately $1.6 \pm 0.1 \mathrm{~mm}$. With the Denim $\left(\varepsilon_{r}=1.8\right.$ and $\tan \delta=$ $0.07)$ it has been designed to have an impedance of $50 \Omega$.

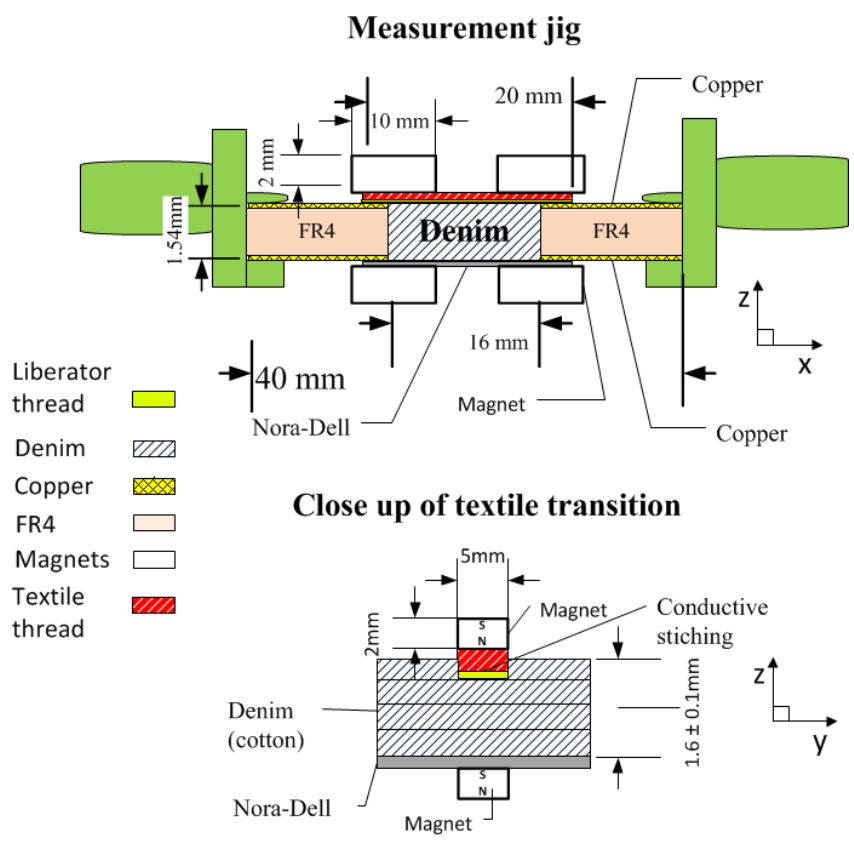

Fig. 1. Measurement jig model

The magnets are $10 \times 5 \times 2 \mathrm{~mm}$ Neodymium Iron Boron $(\mathrm{NdFeB})$ Nickel coated magnets [7], which are used in pairs in each transition to

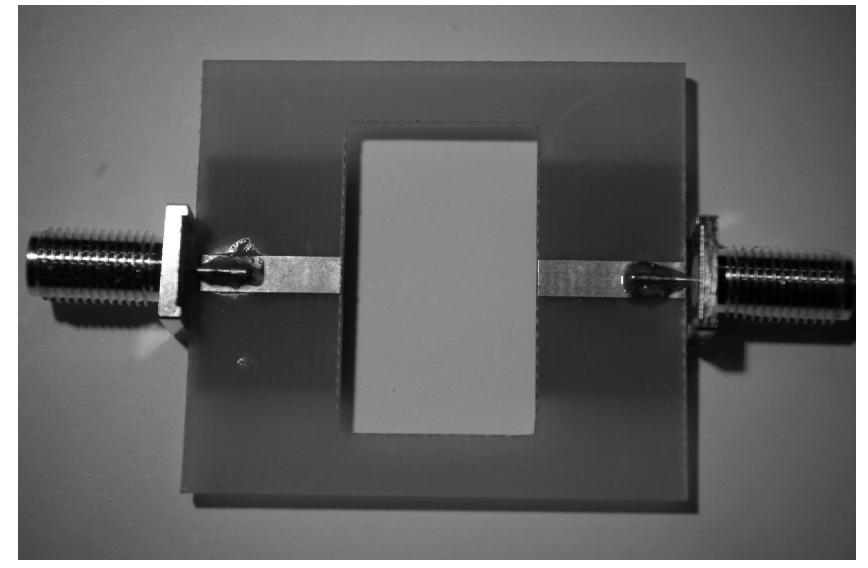

Fig. 2. Board without textile transition

secure firmly the textile transition in place and also to apply contact force between the conductive textile materials and copper, shown in Figures 3 and 4 . Two configurations for the magnets are presented. In one the rectangular magnets are in alignment with the microstrip direction while in the other the magnets are transverse to the microstrip direction.

The system is connected to a Anritsu 37397D Vector Network Analyzer (VNA) via the SMA connectors on both ends of the rigid substrate, with the textile microstrip bridging the gap in the test jig.

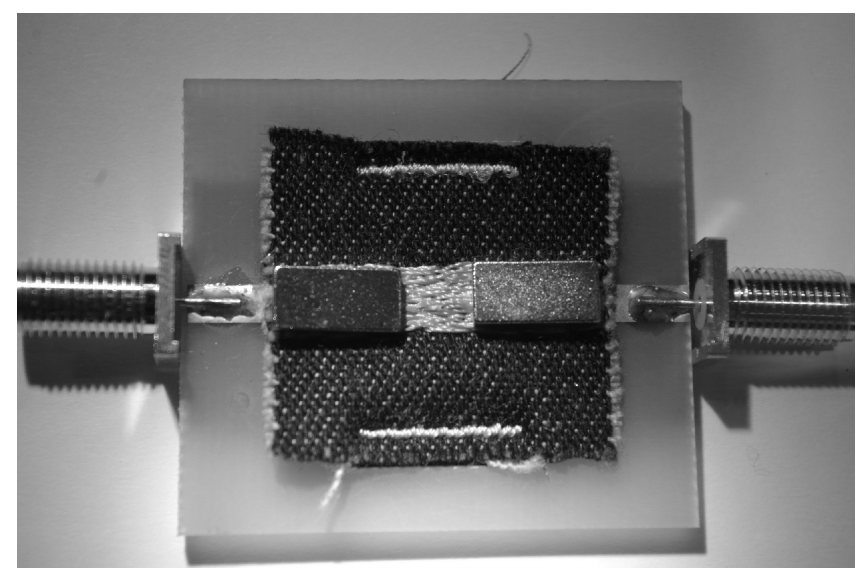

Fig. 3. Textile transition inserted in rigid dielectric - top view

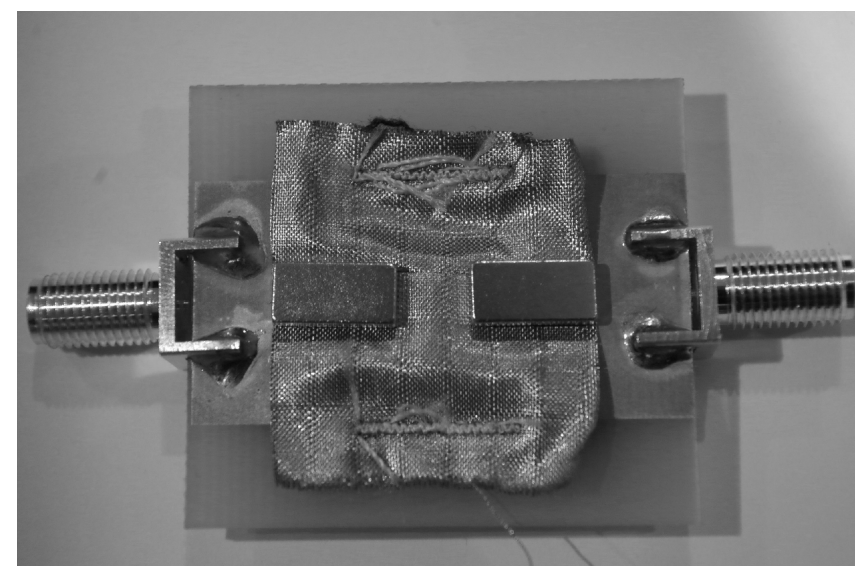

Fig. 4. Textile transition inserted in rigid dielectric - bottom view

Results: Figure 5 shows the measured $\mathrm{S}_{11}$ for the two different magnet configurations compared to a simulation using CST ${ }^{\circledR}$ with the magnets aligned with the microstrip, Figure 6 presents the measured $S_{21}$ results and the simulated values with the magnets aligned to the microstrip. The measured results of the transition sitting on top of a human hand have 
also been presented. Figure 5 has a Reflection Coefficient maximum of $-13 \mathrm{~dB}$ at $2 \mathrm{GHz}$ with an acceptable impedance match up to $3 \mathrm{GHz}$.

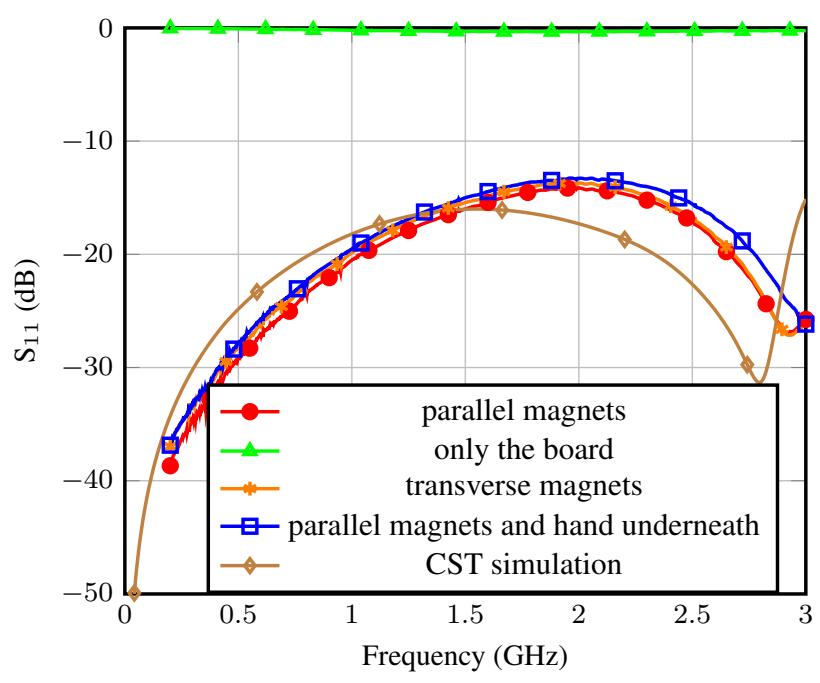

Fig. 5. $\mathrm{S}_{11}$ results

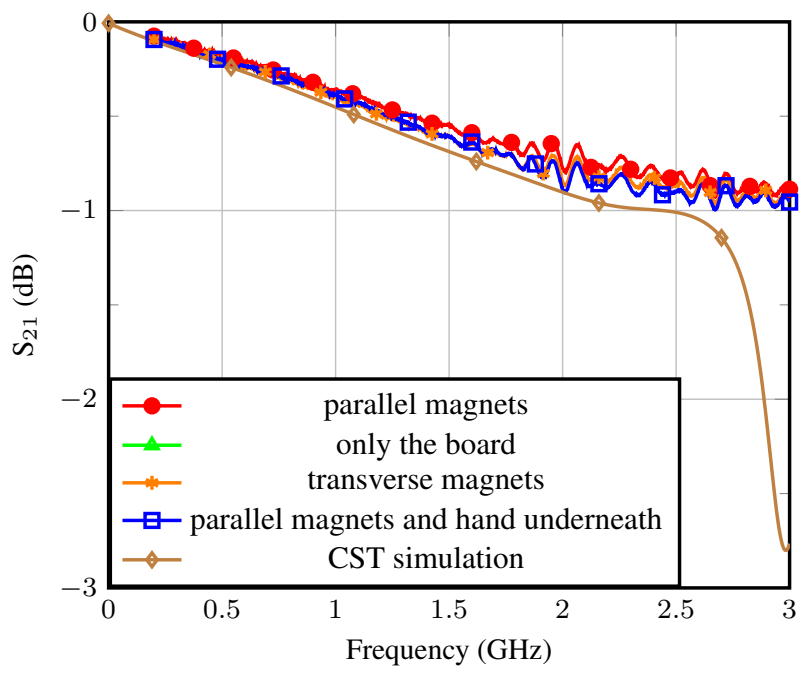

Fig. 6. $\mathrm{S}_{21}$ results with different jig configuration

In Figure 6 the insertion loss values vary from $-0.1 \mathrm{~dB}$ at $0.2 \mathrm{GHz}$ up to $-0.9 \mathrm{~dB}$ at $3 \mathrm{GHz}$ when the magnets are used, which demonstrates a good RF connection. This are the results for two interconnections and a short length of textile line. Future work will be done to measure the insertion loss of a single interconnection.

In both figures the results measured while the transition was resting on top of a human hand do not have a noticeable difference between the measurements where the hand was not present. This indicates that the body has a very small effect on the transition because of the ground plane and, possibly the larger test jig ground plane.

The structure was also measured without the magnets, and without the textile microstrip inserted in the board. For the measurement without the magnets applying contact force on the conductive thread the values of $S_{21}$ are below $-13 \mathrm{~dB}$ and for the measurement without the textile microstrip the value for $S_{21}$ is below $-50 \mathrm{~dB}$, which shows that the magnets are essential to ensure good contact between the copper microstrip and the conductive thread.

Conclusion: A reusable textile connector that allows the connection between textile systems and stardard microwave systems, without the need for an SMA soldered to the textile system has been presented. The connector can be attached and reattached without the use of screws or metal fastening, allowing the easy insertion or removal of electronic systems used in clothes. Integrating the magnets into the fabrics will allow consistency of connection.
It has been shown that the magnets are worthwhile addition to the system and are necessary to apply contact force between the conductive textile microstrip and the rigid substrate microstrip. With a good insertion loss value of $-0.9 \mathrm{~dB}$ at $3 \mathrm{GHz}$ this design might be pushed towards higher frequencies and still have reasonable insertion loss values. As the transition line is microstrip with a ground plane, very little field can extend outside and thus the human body has very little effect on performance.

Fonseca, Duarte S., Seager, Rob D. and Flint, James A. (School of Electronic, Electrical and Systems Engineering, Loughborough University, Loughborough, United Kingdom)

E-mail: d.fonseca@lboro.ac.uk

\section{References}

1 I. Locher, M. Klemm, T. Kirstein, and G. Troster, "Design and characterization of purely textile patch antennas," Advanced Packaging, IEEE Transactions on, vol. 29, no. 4, pp. 777-788, Nov 2006.

2 J. Leśnikowski, "Textile transmission lines in the modern textronic clothes," Fibres \& Textiles in Eastern Europe, vol. 19, no. 6, p. 89, 2011.

3 R. Seager, A. Chauraya, S. Zhang, W. Whittow, and Y. Vardaxoglou, "Flexible radio frequency connectors for textile electronics," Electronics Letters, vol. 49, no. 22, pp. 1371-1373, Oct 2013.

4 S. Chen, C. Fumeaux, D. Ranasinghe, and T. Kaufmann, "Paired snapon buttons connections for balanced antennas in wearable systems," Antennas and Wireless Propagation Letters, IEEE, vol. PP, no. 99, pp. 1-1, 2014.

5 "Liberator ${ }^{\mathrm{TM}}$ conductive fiber," http://www.metalcladfibers.com/ liberator-fiber/, accessed: 21/11/2014.

6 "Nora dell-cr conductive metallized nylon fabric," http://www. shieldextrading.net/pdfs/NoraDell\%20CR.pdf, accessed: 21/11/2014.

7 "Characteristics of ndfeb magnets," http://www.ndfeb-info.com/ characteristics.aspx, accessed: 21/11/2014. 